\title{
Comparative study between percutaneous pinning and ligamentotaxis using external fixator in the management of distal end radius fracture in adults: a prospective study
}

\author{
Sridhar D. K., Raghavendra T. S., Jaipalsinh R. Mahida*
}

\begin{abstract}
Department of Orthopaedics, Shridevi Institute of Medical Sciences \& Research Hospital, Sira Road, Tumkur, Karnataka, India
\end{abstract}

Received: 18 November 2016

Revised: 18 January 2017

Accepted: 31 January 2017

\section{*Correspondence:}

Dr. Jaipalsinh R. Mahida,

E-mail: dr.jaipalsinhmahida@gmail.com

Copyright: ( $)$ the author(s), publisher and licensee Medip Academy. This is an open-access article distributed under the terms of the Creative Commons Attribution Non-Commercial License, which permits unrestricted non-commercial use, distribution, and reproduction in any medium, provided the original work is properly cited.

\begin{abstract}
Background: Fractures of distal end of radius are beginning at the proximal end of pronator quadratus and ending at the radio-carpal articulation. The final aim in the management of comminuted intra-articular fractures of distal radius is to restore normal function. Recognition of patterns that are inherently unstable and therefore necessitate additional forms of fixation to secure and maintain reduction and prevent late collapse is the key for successful management of the more complex fractures of distal radius. The aim is to study the functional outcome of surgical management of comminuted intra-articular fractures of distal end radius by comparing 2 different methods of surgical interventions.

Methods: In study of 30 cases treated in period from March 2008 to September 2009 at St. Martha's Hospital by ligamentotaxis and percutaneous pinning, all patients with compound fractures, Frykman's IV, V, VI, VII and VIII, comminuted fractures and in fractures where reduction was lost following closed reduction and POP application were taken into consideration.

Results: The average age in males were 41.35 years and female were 35 years. $12(40 \%)$ fractures were type VII, 6 (20\%) were type VIII, 9 (30\%) were type IV and 3 cases $(10 \%)$ was type V. functional results in ligamentotaxis group (G1) 7 cases had excellent results (47\%), in percutaneous pinning (G2), 3 cases had excellent result (20\%). In ligamentotaxis group (G1) 3 had good results (20\%), in percutaneous group (G2) 6 had good results (40\%). In ligamentotaxis group (G1) 5 had poor results (33\%), in percutaneous pinning group (G2) 6 had poor results $(40 \%)$.

Conclusions: In comparative studies, external fixation with percutaneous pinning consistently achieves better anatomical results as compared to percutaneous pinning alone. In our study, also this technique has shown satisfactory result that lead to high rate of return to pre-injury status, high level of patient satisfaction and low rate of complications.
\end{abstract}

Keywords: Distal end radius fracture, Ligamentotaxis, Percutaneous pinning, Frykman classification, Older criteria

\section{INTRODUCTION}

Distal radial fractures crush the mechanical foundation of man's most elegant tool, the hand. No other fracture has a greater potential to devastate hand function and no metaphysis of bone is embraced by more precious soft tissues. The same ligaments, retinaculum, tendons and periosteum that envelope the fractures and help to mold its reduction during ligamentotaxis create a surgical barrier to open reduction. ${ }^{1}$ The term fractures of distal end of radius refers to fractures beginning at the proximal end of pronator quadratus and ending at the radio-carpal articulation. 
Fractures of the distal radius have been associated with a colorful history since their first description by Ponteau in 1783 and Colles' in 1814, Cooney has stated "Fractures of the distal radius which are stable i.e., extra articular and not comminuted are different from fractures which are unstable i.e., intra articular and comminuted., ${ }^{2,3}$ Therefore, different treatment modalities are required for the types of fractures. The final aim in the management of comminuted intra articular fractures of distal radius is to restore normal function. The best method of obtaining and maintaining an accurate restoration of articular anatomy however remains a topic of considerable controversy. Recognition of patterns that are inherently unstable and therefore necessitate additional forms of fixation to secure and maintain reduction and prevent late collapse is the key for successful management of the more complex fractures of distal radius.

External fixation in combination with percutaneous pinning has proved to be effective in the management of unstable intra articular fractures of distal radius, but has also linked with an unacceptably high rate of complications in some series. ${ }^{4}$ The aim is to study the functional outcome of surgical management of comminuted intra articular fractures of distal end radius by comparing 2 different methods of surgical interventions.

\section{METHODS}

In our study 30 cases were treated in the period from March 2008 to September 2009 at St. Martha's Hospital by ligamentotaxis and percutaneous pinning. All patients with compound fractures, Frykman's IV, V, VI, VII and VIII, comminuted fractures and in fractures where reduction was lost following closed reduction and POP application were taken into consideration. A careful history was elicited and commonest mode of injury was fall on outstretched hand with wrist in dorsiflexion. A careful clinical assessment of skeletal and soft tissue injuries and general condition of the patient was done. The clinical examination gave a clue to determine, whether the fracture was caused by direct or indirect violence. In direct violence, there were abrasions or wound over the wrist. Clinical diagnosis was confirmed by taking anteroposterior and lateral radiographs. All the patients were immobilized in a dorsal POP slab until the time of surgery. All the surgeries were done under general anaesthesia or brachial block, with minimal exposure of bones for placement of pins. Follow-up was done for five months from the day of surgery. Active finger, elbow and shoulder exercises are encouraged postoperatively to promote circulation, avoid oedema, stiff fingers, stiff elbow and shoulder. Postoperative check X-ray was taken and a note of radial height, radial angulation and palmar angulation were made. Implants used were Schanz pins (size: 2.5 mm-3.5 mm), Kirschner wires (size: $2 \mathrm{~mm}-3.5 \mathrm{~mm}$ ), connecting rods and clamps.

After reduction, the external fixator was applied with wrist in ulnar deviation and volar flexion for dorsal fractures and dorsiflexion in case of volar fractures. Any displaced fragments were fixed with 'k'-wires. After surgery, the limb was immobilized in cuff and collar sling. Clinical assessment of range of motion was reviewed at weekly intervals. Second check X-ray was taken at 4 weeks after surgery. A note of articular congruity, radial height, radial and palmar angulation were made. Fixator was removed between 6-8 weeks interval. K-wire wires were removed between 6-10 weeks interval. No additional splintage was provided. After removal, wrist motion was measured by a goniometer with elbow flexed 90 degrees and compared with uninjured side.

\section{Procedure}

\section{Percutaneous pinning}

Percutaneous pinning techniques are an attempt to the therapeutic gap between external fixators and pure casting alone. Percutaneous pinning provides adequate fixation that invokes minimal interference with the functioning of adjacent joints and that it is associated with a minimal rate of complications. ${ }^{6-8}$

The goals of percutaneous pinning are the least number of days in a cast or splint during the healing phase, minimal complications from pin migration, avoidance of fracture displacement or settling, application of the technique to all fractures that can be reduced by ligamentotaxis, avoidance of tendon ruptures, irritation or adhesions, a minimal number of surgical procedures for subsequent pin removal, avoidance of pin breakage, minimal use of image intensifier, avoidance of sensory nerve damage, avoidance of pin tract infection if left percutaneously or skin protrusion if cut subcutaneously, avoidance of limitation in finger, wrist and forearm movements, avoidance of pin dysfunction or dystrophy.

Six basic percutaneous techniques are pure radial styloid pinning - Lambotte (1908), ulnar - radial pinning without fixation of the distal radio ulnar Joint - Depalma (1952), radial styloid pinning and dorsal radial pinning - Stein (1975), radial styloid and ulnar - radial pinning of posteromedial fragment - UHL (1976), Kapandji double intrafocal pinning into the fracture surface and ulnar radial pinning with fixation of distal radio ulnar joint Rayhack (1989), This technique is applicable to any distal radius fracture that can be reduced by ligamentotaxis and that has been proven to be unstable following initial reduction or that is believed to be inherently unstable.

Complications of percutaneous pinning are fracture redisplacement (post pinning), loss of reduction, pain dysfunction, radial sensory nerve irritation, Sudek's osteodystrophy (RSD), pin tract infections, poor pin placement, pin migration, pin loosening, carpal tunnel syndrome, extensor tendon rupture. 
The researchers have concluded that the procedures in which ulna is engaged provide superior resistance to fracture displacement and that transulnar radial pins that cross the radial fracture impact greater stability than those that do not.

A study concluded that two-pin Clancy method was the least stiff, followed by radial styloid pinning (Lambotte). The stiffest technique was that of transulnar pinning (Rayhack).

A clearly unstable fracture should be treated aggressively with percutaneous pinning. It is not necessary to wait until the fracture collapses to proceed with a percutaneous procedure. In our series, for most of the cases Stein's method of percutaneous pinning was followed. The Kirschner wires used, the size was varying from $2 \mathrm{~mm}$ to $3.5 \mathrm{~mm}$ diameter.

\section{External fixation}

External fixation has shown to be effective in the surgical management of unstable intra-articular fractures of the distal radius, but has also been linked with an unacceptably high rate of complications in some series. ${ }^{9}$ The successful use of external fixation necessitates careful assessment of the fracture pattern, appropriate patient selection, a careful and meticulous surgical approach, appropriate choice of fixation device and pins, judicious use of augmentation with internal fixation and bone grafting, aggressive early rehabilitation and careful post-operative monitoring. Hallmarks of unstable intra articular fracture of distal radius include significant volar or dorsal comminution, more than $2 \mathrm{~mm}$ spread and depression of articular fragments, more than $10^{\circ}$ angulation of the major fragments, extension of fracture into radio-carpal and radio-ulnar joints and occasionally an ulnar neck fracture.

Studies conducted by Gartland and Werley showed that $88 \%$ of fractures involved the articular surface of the radiocorpal joint and they concluded that closed reduction and cast immobilization were inadequate for many intra-articular fractures. They followed Frykman's classification in the treatment of distal radial fractures. More than $80 \%$ of fractures treated by external fixation were Frykman's type VII and VIII. External fixation relies on ligamentotaxis to apply traction and correct displacement. Indications for external fixator application were Frykman's type III, IV, V, VII and VIII and decrease in radial height of greater than 3-4 mm.

\section{Surgical technique}

A limited open surgical approach is ideal to avoid damage to delicate soft tissues in the forearm and hand. ${ }^{5,9}$ This technique involves two $2.5 \mathrm{cms}$ incisions; one centered approximately $10 \mathrm{cms}$ proximal to the radial styloid overlying the radial aspect of the forearm and one overlying the dorsoradial aspect of the base of the index metacarpal.

The external fixation device can then be applied to the fixator pins in its completely loosened state. Gentle longitudinal traction without severe hyperflexion or hyper extension and manual molding of the fracture fragments is performed. When the majority of the distal fracture fragments are displaced dorsally, gentle flexion and ulnar deviation can be applied as well. When more volar displacement is present gentle supination in slight dorsiflexion can be added to achieve reduction. At this point, the fixation device is locked into place and reduction checked under image intensifier. The fixator device can be expected to maintain overall length and angular and rotational alignment.

The hand and wrist can then be realigned in a neutral position with the forearm. Tension across the wrist should provide enough ligamentotaxis so that on an antero-posterior radiograph the radio-carpal articulation is seen to be $1 \mathrm{~mm}$ wider than mid carpal joint. At the end of surgical procedure, the hand and forearm are placed in a bulky dressing. No cast or splint is needed. The fingers are left free to go through full range of motion.

Merits of ligamentotaxis are the forces of deformation are neutralized by pins directly placed on the bone, Pin placement and frame configuration determines fracture alignment, distraction can be done intra-operatively as well as postoperatively depending on fracture status, since the assembly spans the wrist the extrinsic muscle forces cannot act at the fracture site, gravitational forces on the fragments are neutralized due to direct hold on the bone, reduction of stasis is achieved by elevation and active movements during treatment, the medial ligament complex injury and inferior radio-ulnar joint dislocation can be reduced and maintained by a medial wrist spanning assembly.

The force of ligamentotaxis by external fixator can counter all the extrinsic deforming forces and helps to reduce the fracture as described but maintenance of reduction is not easy for the following reasons:

- The stretch within ligaments leads to neohistiogenesis and with this the ligaments get elongated during course of time. This leads to gradual diminution of corrective force and extrinsic deforming forces may cause recurrence of deformity.

- The bone loss or crushing of bone leads to bone gaps and in cancellous bone the bridging callus is inadequate healing occurs only in the contact area and is therefore incomplete.

Complications of external fixator are faulty pin placement causing iatrogenic neurovascular injuries and joint stiffness - impalement and rupture of tendons, ligaments and capsular structures, component failure caused by misuse and wrong application, breakages, 
deformation, malfunctioning of components, inadequate instrumentation and instruction, pin problems - infection, loosening, breakage, fracture at the pin site, finger, wrist, elbow stiffness and shoulder hand syndrome, reflex sympathetic dystrophy should be suspected when pain swelling and stiffness are out of proportion to the severity of injury, post-traumatic arthritis.

Functional assessment of results was done by Older et al, method of functional results which considered strength, pain and limitation of movements. Like Frykman, they also believed the residual deformity did not significantly contribute to functional outcome.

For convenience, we have grouped the modalities into two groups: G1-Ligamentotaxis and G2-Percutaneous pinning.
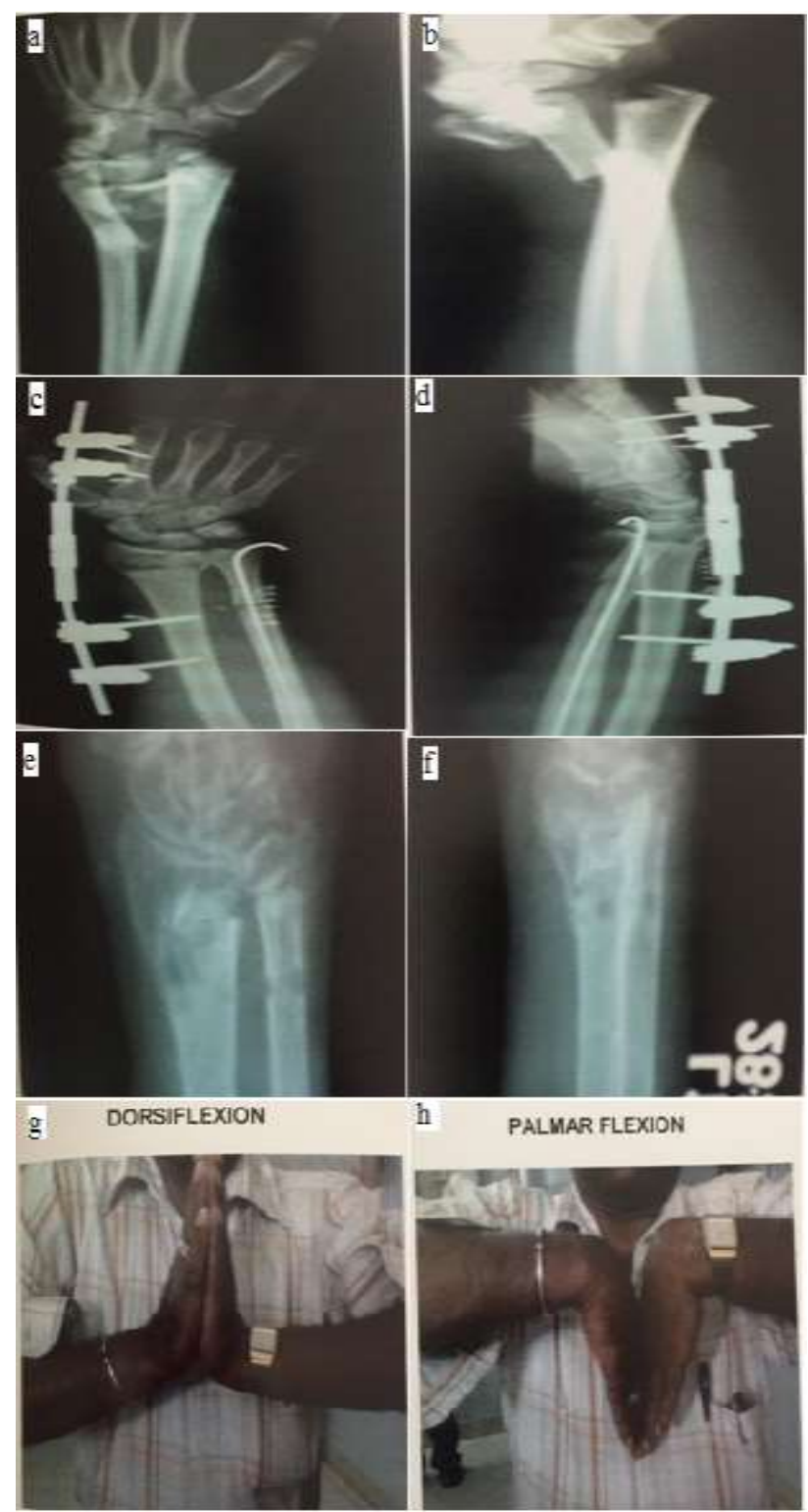

h

PALMAR FLEXION

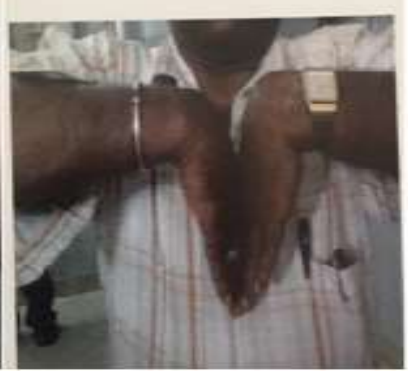

Figure 1: Ligamentotaxis (G1). (a, b) Pre-operative Xray; (c, d) Post-operative X-ray; (e, f) After 8 weeks $\mathrm{X}$-ray; (g, h) Clinical photos of functional results.

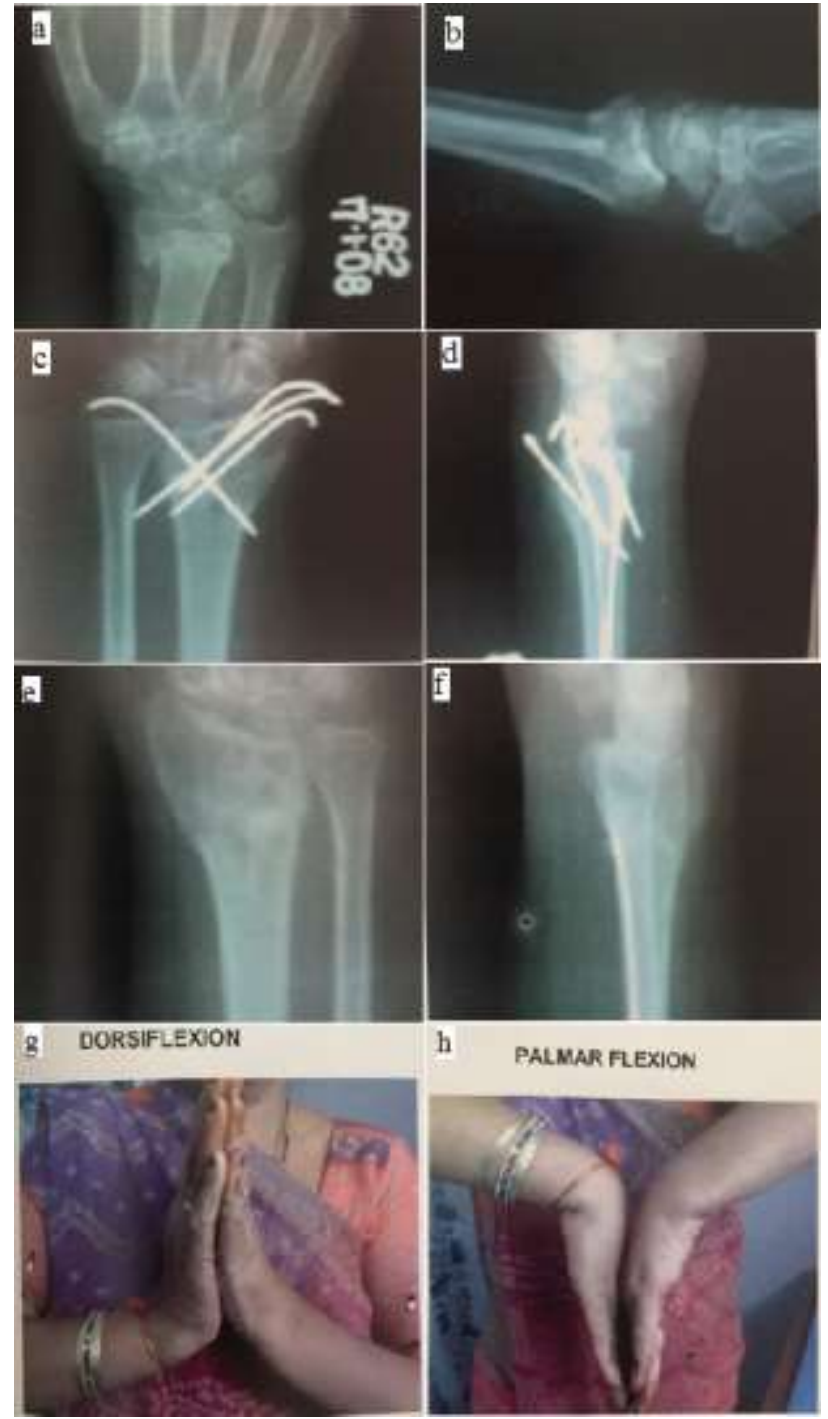

Figure 2: Percutaneous pinning (G2). (a, b) Preoperative X-ray; (c, d) Post-operative X-ray; $(e, f)$ After 8 weeks X-ray; $(g, h)$ Clinical photos of functional results.

\section{RESULTS}

This study consists of 30 cases of comminuted intra articular fractures of distal radius treated surgically by two surgical modalities during the study period. All cases were available for follow up. The average age in males were 41.35 years and female were 35 years. There were 20 males $(66.6 \%)$ and 10 females (33.3\%). In this study, 22 cases $(73.3 \%)$ were due to indirect trauma. Fall on outstretched hand was the cause. In 8 cases, direct trauma was the mechanism of injury, which includes road traffic accidents.

Frykman's classification was followed, $12 \quad(40 \%)$ fractures were type VII, 6 (20\%) were type VIII, 9 (30\%) were type IV and 3 cases (10\%) was type V. 9 patients $(30 \%)$ had associated fracture. There were 4 cases of fracture ulna, 1 case of fracture humerus, 1 case with fracture calcaneum, 1 case with tendon injury and 1 case 
with \# vertebra, 1 case \# ankle, 1 case with \# of contralateral radius.

There were 7 cases with pain, persistent or occasional, 3 from ligamentotaxis group (G1) and 4 from percutaneous pinning (G2). Loss of motion at the wrist was noted in 3 cases, 2 cases from ligamentotaxis group (G1) and 1 case in percutaneous pinning. Infection or pin loosening was seen in 1 case operated by percutaneous pinning. Reflex sympathetic dystrophy was seen in 1 case operated by ligamentotaxis. Pain and loss of motion at the wrist was seen in 2 cases - 1 case in ligamentotaxis group (G1), 1 case in percutaneous pinning $(\mathrm{G} 2)$.

The difference in the meantime of healing between ligamentotaxis (G1) (6.47 weeks) and percutaneous pinning (7.0 weeks) which is more or less the same and this difference is statistically not significant $(\mathrm{p}<0.05)$. The least time of healing was seen in the ligamentotaxis group (G1).

Based on Older et al, criteria, functional results were analysed as given in Table 2. In ligamentotaxis group (G1) 7 cases had excellent results $(47 \%)$, in percutaneous pinning (G2), 3 cases had excellent result (20\%). In ligamentotaxis group (G1) 3 had good results (20\%), in percutaneous group (G2) 6 had good results $(40 \%)$. In ligamentotaxis group (G1) 5 had poor results (33\%), in percutaneous pinning group (G2) 6 had poor results $(40 \%)$.

Table 1: Time Taken for bony union.

\begin{tabular}{|c|c|c|c|c|}
\hline \multirow{2}{*}{$\begin{array}{l}\text { Time } \\
\text { taken in } \\
\text { weeks }\end{array}$} & \multicolumn{2}{|c|}{$\begin{array}{l}\text { Ligamentotaxis } \\
\text { (G1) }\end{array}$} & \multicolumn{2}{|c|}{$\begin{array}{l}\text { Percutaneous } \\
\text { pinning (G2) }\end{array}$} \\
\hline & $\begin{array}{l}\text { No. of } \\
\text { cases } \\
(n=15)\end{array}$ & $\%$ & $\begin{array}{l}\text { No. of } \\
\text { cases } \\
(n=15)\end{array}$ & $\%$ \\
\hline 6 & 7 & $47 \%$ & 9 & $60 \%$ \\
\hline 7 & 3 & $20 \%$ & 1 & $7 \%$ \\
\hline 8 & 5 & $33 \%$ & 5 & $33 \%$ \\
\hline Total & 15 & $100 \%$ & 15 & $100 \%$ \\
\hline
\end{tabular}

Table 2: Comparison of G1 and G2 grading.

\begin{tabular}{|lllll|}
\hline Grade & $\begin{array}{l}\text { Ligamentotaxis } \\
\text { (G1) }\end{array}$ & $\begin{array}{l}\text { No.of } \\
\text { cases } \\
(\mathrm{n}=15)\end{array}$ & $\%$ & $\begin{array}{l}\text { Percutaneous } \\
\text { pinning (G2) }\end{array}$ \\
\hline Excellent & 7 & $47 \%$ & $\begin{array}{l}\text { No. of } \\
\text { cases } \\
(\mathrm{n}=15)\end{array}$ & $\%$ \\
\hline Good & 3 & $20 \%$ & 6 & $20 \%$ \\
\hline Poor & 5 & $33 \%$ & 6 & $40 \%$ \\
\hline Total & 15 & $100 \%$ & 15 & $100 \%$ \\
\hline
\end{tabular}

\section{DISCUSSION}

30 cases of comminuted fracture of distal end radius were treated by two different modalities namely ligamentotaxis and percutaneous pinning. Most of the cases treated with ligamentotaxis were supplemented by intrafocal pinfixation. These cases were followed up for an average of 5 months. These cases were of different age group, occurred in both sexes, and fractures were of different types.

The average age in this series was 41 years for males. The fractures were common in the age group 41-50 years of age. The average age in a study of 132 fractures conducted by Jakim et al, showed that the average of all cases was 35 years. ${ }^{10}$ In a study of 43 fractures in 40 patients conducted by Knirk et al, showed the average age was 27.6 years. ${ }^{11}$ In a study conducted by Bradway et al between 1976 and 1986, the average age was 40 years. $^{12}$ In another study of 40 patients conducted by Horesh et al between 1983 and 1987, the average age was 48 years. $^{13}$

There were 20 males and 10 female patients, showing male preponderance. The sex distribution in a study by Jakim et al there were 71 men and 44 women. ${ }^{10}$ In a study by Jess et al there were 9 men and 4 women. ${ }^{14}$ In a study conducted by William B et al there were 38 men and 22 women. ${ }^{15}$

Majority of patients sustained fracture from fall on outstretched hand $(73.3 \%)$. The other mode of injury was due to road traffic accidents $(26.7 \%)$. In our series, most of the fractures were Frykman type VII and VIII and it constituted $60 \%$. In a study conducted by Jessi et al, 6 of the 13 fractures were Frykman type VII and VIII. ${ }^{14}$ In another study by Horesh et al, 33 of 39 fractures were Frykman type VII and VIII. ${ }^{9}$ In a study conducted by Jupiter et al 44 of 49 fractures were Frykman type VII and V1ll. ${ }^{16}$ The remaining fractures in our series were Frykman type IV and V (40\%).

In the present series $70 \%$ of the patients were only comminuted intra articular distal end radius, while $30 \%$ had associated injuries. In Jakim series, $81.8 \%$ had only comminuted intra articular fracture distal radius ${ }^{6}$, in Richard et al, series it was $75.6 \%$, in William et al series it was $50 \%^{3}$ and in Steffen $\mathrm{J}$ et al series it was $50.9 \%$.

In our series, complications seen were 7 cases with pain, 3 in ligamentotaxis $(\mathrm{G} 1)$ and 4 in percutaneous pinning (G2) group. 3 cases with loss of motion-2 in ligamentotaxis (G1) and 1 in percutaneous pinning (G2) group. Infection was seen in 1 patient in percutaneous pinning group (G1). 2 cases had pain with loss of motion, one in each group. 1 case of reflex sympathetic dystrophy was seen in percutaneous pinning group (G2). In our series, percutaneous pinning (G2) was associated with higher complications.

The time taken for bone union was 6.47 weeks in G1 group, 6.7 weeks in G2 group, p value is $<0.05$, not significant. So, ligamentotaxis group (G1) has taken the least time for bone union. This is probably due to 
preservation of fracture hematoma, absence of periosteal stripping and a good reduction of the fracture with transfixation of the fracture fragments with Kirschner wires in addition to external fixation particularly helpful in holding articular fragments that had little metaphyseal support. External fixator is applied to provide neutralization of compressive forces acting across the corpus on the small fracture fragments. After restoration of appropriate radial length, volar tilt and angle of inclination, precise articular restoration can be achieved by percutaneously inserting a Kirschner wire and using it as a joy stick to maneuver the articular fragments into position. A Kirschner wire is then inserted at the tip of the radial styloid and anchored to into the ulnar side of the more proximal shaft fragment. Additional percutaneous Kirschner wires are inserted transversely through the radial styloid fragment directly under the subchondral bone to provide subchondral support. It allowed early mobilization of shoulder, elbow and fingers, which is important for early functional recovery. Patients compliance was good, complication are minor, easily treated and do not affect outcome. Outcome is likely improved with shorter duration of external fixation. Supplemental K-wire fixation appears to be a favourable adjunct to external fixation, allowing earlier fixator removal.

In our series, we had 10 cases with excellent (33\%) results with good articular congruity and miner degrees of pain and slight limitation of motion, of which G1 were 7 (70\%) and G2 were $3(30 \%)$. Good results were $9(30 \%)$ of which G1 were $3(33 \%), \mathrm{G} 2$ were $6(66 \%)$. Good to excellent results can be attributed to good reduction, most of the patients with excellent results were younger, fixator removal was done early resulting in minimal stiffness and pain. All the fractures with this result were closed type. Poor results were $11(36.3 \%)$ mainly due to difficulty in getting good articular congruity with persistent pain, significant loss of motion, among them $45.4 \%$ are in G1 and $54.6 \%$ are in G2 groups. Poor results can be attributed to severe degree of comminution. Most of the fractures were open type. Most of the cases had other associated major injuries.

\section{CONCLUSION}

Fixations of comminuted articular fractures of distal radius with multiple Kirschner wires alone are insufficient to withstand forces across the fracture site to prevent fracture collapse. It is well-suited for younger patients who have unstable but reducible extra or intra articular distal radius fractures and which provide adequate fracture stability and soft tissue and vascular preservation, in addition to minimal patient morbidity. Ligamentotaxis neutralizes the compressive forces generated across the wrist joint, provides sufficient rigidity until bony healing occurred, thus allowing realignment of severely comminuted fractures. In comparative studies, external fixation with percutaneous pinning consistently achieves better anatomical results as compared to percutaneous pinning alone. In our study, also this technique has shown satisfactory result that lead to high rate of return to pre-injury status, high level of patient satisfaction and low rate of complications. Successful management of complex distal radial fractures necessitates careful assessment of fracture pattern, appropriate patient selection, a careful and meticulous surgical approach, appropriate choice of fixation device and pins, judicious use of augmentation with internal fixation, aggressive early rehabilitation and careful postoperative monitoring. The surgeon well oriented with the above principle will be in a position to optimize the outcome of the patients.

Funding: No funding sources

Conflict of interest: None declared

Ethical approval: The study was approved by the institutional ethics committee

\section{REFERENCES}

1. Agee JM. Distal radius fractures: Multiplanar ligamentotaxis. Hand Clin. 1983;9:577-85.

2. Cooney WP, Linscheid RL, Dobyns JH. External pins fixation for unstable Colles' fractures. JBJS. 1979;61:840.

3. Cooney WP. Fractures of distal radius. Orthop Clin N Am. 1993;24(2):213.

4. Kaempfee FA, Walker KM. External fixation for distal radius fractures: Effect of distraction on outcome. Clin Orthop Related Res. 2000;380:220-5.

5. Geissler WB, Fernandez DL. Percutaneous and limited open reduction of the articular surface of distal radius. J Orthop Trauma. 1991;5:255.

6. Green DP. Pins and plaster treatment of comminuted fractures of distal end of radius. JBJS. 1975;57:304-10.

7. Rayhack JM. The history and evolution of percutaneous pinning of displaced distal radius fractures. Orthop Clin N Am. 1993;24(2):287-300.

8. Benoist LA, Freeland AE. Buttress pinning in the unstable distal radial fracture. J Hand Surg $(\mathrm{Br})$. 1995;20(1):82-96.

9. Seitz Jr WH. External fixation of distal radius fractures. Orthop Clin N Am. 1993;24(2):255-63.

10. Jakim I, Pieterse HS, Sweet. External fixation of intraarticular fractures of the distal radius. J Bone Joint Surg (Br). 1991;73:302-6.

11. Knirk JL, Jupiter JB. Intraarticular fractures of distal radius in young adults. JBJS. 1986;68:647-59.

12. Bradway JK, Amadio PC, Cooney WP. Fracture of distal radius. JBJS. 1986;71:839-47.

13. Horesh Z, Volpin G, Hoerer D, Stein H. The surgical treatment of severe comminuted intraarticular fracture of distal radius with the small AO external fixation device. Clin Orthop Related Res. 1991;263:147-53.

14. Lipton H, Jupiter JB. The operative treatment of intraarticular fractures of the distal radius. Clin Orthop Related Res. 1993;292:48-61. 
15. Leibovic SJ, Geissler WB. Treatment of complex intraarticular distal radius fractures. Orthop Clin N Am. 1994;25(4):685-706.

16. Jupiter JB, Fernandez DL, Toh CL, Feilman T, Ring D. Operative treatment of volar intraarticular fractures of the distal radius, JBJS (Am). 1996;78(12):1817-28.
Cite this article as: Sridhar DK, Raghavendra TS, Mahida JR. Comparative study between percutaneous pinning and ligamentotaxis using external fixator in the management of distal end radius fracture in adults: a prospective study. Int J Res Orthop 2017;3:235-41. 